\title{
Heterochronic genes in plant evolution and development
}

\section{Koen Geuten* and Heleen Coenen}

Department of Biology, Laboratory of Molecular Plant Biology, University of Leuven, Leuven, Belgium

\section{Edited by:}

Jill Christine Preston, University of Vermont, USA

\section{Reviewed by:}

Jeanne Marie Harris, University of Vermont, USA

Andrew Doust, Oklahoma State

University, USA

\section{${ }^{*}$ Correspondence:}

Koen Geuten, Department of Biology, Laboratory of Molecular Plant Biology, University of Leuven, Kasteelpark Arenberg 31, 3001 Leuven, Belgium e-mail:koen.geuten@bio.kuleuven.be
Evolution of morphology includes evolutionary shifts of developmental processes in space or in time. Heterochronic evolution is defined as a temporal shift. The concept of heterochrony has been very rewarding to investigators of both animal and plant developmental evolution, because it has strong explanatory power when trying to understand morphological diversity. While for animals, extensive literature on heterochrony developed along with the field of evolution of development, in plants the concept has been applied less often and is less elaborately developed. Yet novel genetic findings highlight heterochrony as a developmental and evolutionary process in plants. Similar to what has been found for the worm Caenorhabditis, a heterochronic gene pathway controlling developmental timing has been elucidated in flowering plants. Two antagonistic microRNA's miR156 and miR172 target two gene families of transcription factors, SOUAMOSA PROMOTOR BINDING PROTEIN-LIKE and APETALA2-like, respectively. Here, we propose that this finding now allows the molecular investigation of cases of heterochronic evolution in plants. We illustrate this point by examining microRNA expression patterns in the Antirrhinum majus incomposita and choripetala heterochronic mutants. Some of the more beautiful putative cases of heterochronic evolution can be found outside flowering plants, but little is known about the extent of conservation of this flowering plant pathway in other land plants. We show that the expression of an APETALA2-like gene decreases with age in a fern species. This contributes to the idea that ferns share some heterochronic gene functions with flowering plants.

Keywords: microRNA172, microRNA156, choripetala, incomposita, Ceratopteris, heterochrony, APETALA2, SPL

\section{INTRODUCTION}

Time is a fundamental aspect of all developmental processes. It plays a role in different types of development, such as growth or differentiation and at different scales, whether it be cellular, at the tissue or at the organ level (Moss, 2007). In the discipline of evolution and development, evolutionary changes in the regulation of developmental time or "heterochrony" were once proposed to explain much of morphological diversity (Gould, 1977). To test whether this is indeed the case, it is necessary to be able to unambiguously identify cases of heterochrony. Developmental time is now known in several organisms to be controlled by endogenous mechanisms that interact with endogenous and environmental stimuli (Slack and Ruvkun, 1997, 1998; Moss, 2007; Huijser and Schmid, 2011). Also in plants, a "heterochronic pathway" has been elucidated (Chuck et al., 2007a,b; Wu et al., 2009). For both plants and animals, several classic examples of morphological evolution have been proposed to be heterochronic in nature, suggesting that the regulation of a heterochronic pathway has evolved in these instances. The discovery of a heterochronic pathway contributes to the testability of these hypotheses of regulatory evolution. Ultimately, it should become possible to answer such questions as, "Is evolution of developmental timing frequent in plants?, "Can it explain most of morphological diversity?," "What types of morphological consequences can evolution of developmental timing have?" Or more generally, is heterochrony indeed such an important developmental process in the evolution of morphology? Here we mostly review some of the elaborate literature on heterochronic evolution and how it can be applied in the field of plant evolution and development.

\section{TIME AND RATE IN PLANT DEVELOPMENT}

In contrast to animal development, plant development entails the continuous development of new organs as time progresses. This open developmental shoot system generates different organs depending on the age of the plant. The different types of above ground leaf-like organs that develop result in a "heteroblastic" sequence observable in the mature plant (Allsopp, 1967; Zotz et al., 2011). This sequence starts with embryonic leaves or cotyledons, then juvenile leaves develop, these transition into adult leaves and finally inflorescence leaves or bracts develop. The floral organs can be seen as a continuation of this sequence of different leaf types, with sepals and petals still resembling leaves. While stamens and carpels do not resemble leaves in most species, they can still be interpreted as such (Figure 1; von Goethe, 1790; Arber, 1937; Takhtajan, 1976). A similar sequence can be observed in monoecious inflorescences, in which lower positioned unisexual male flowers develop earlier than unisexual female flowers. Also in cleistogamous species, the different floral types are associated with a timed change in identity resulting in either closed flowers that obligately self or open flowers that can outcross (Lord and Hill, 1987).

Regular time obviously progresses at a constant rate. However, what is called developmental time or age can be fast or slow, meaning that development can be accelerated or retarded relative 


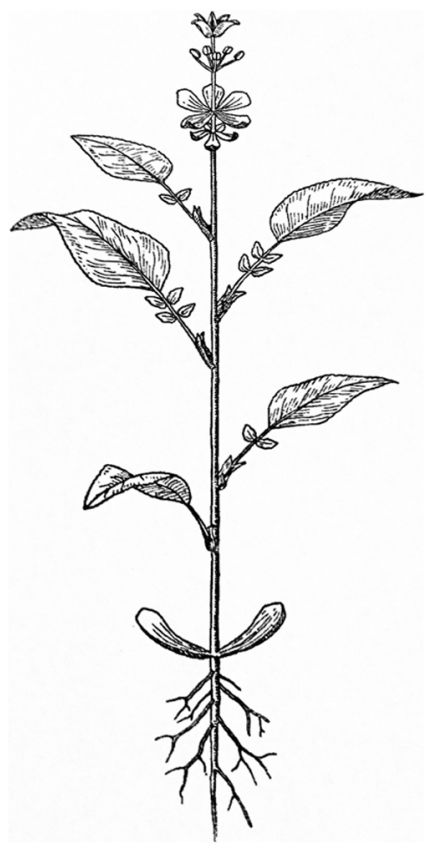

FIGURE 1 |The annual plant as viewed by Goethe (represented by Troll).

to regular time or relative to other developmental events (Poethig, 2003). Developmental time or, e.g., plastochron length in case of leaves, is the time that passes between the development of two successive leaves. Developmental rate in plants is counted in numbers of organs that develop per unit of time. Plants are special in this sense because developmental rate can be easily measured in the adult form of the plant as an average number of organs that has developed in a certain period of time, which makes plants a good system to study developmental time.

\section{DEFINITIONS OF HETEROCHRONY}

The term heterochrony was first introduced by Ernst Haeckel in the second half of the 19th century (Smith, 2003). It was used to describe deviations from his well-known "Biogenetic Law" which states that the sequence of developmental events largely recapitulates the sequence of events in the evolutionary history of the species. In several books, de Beer uncoupled heterochrony from recapitulation and used the term to denote a relative displacement of a character in its timing of development when comparing two related species (De Beer, 1951). Gould (1977), in his reevaluation of the concept, focused heterochrony again on parallels between or reverse relations of ontogeny and phylogeny and emphasized size and shape as the measures to detect heterochrony. The way the concept has most often been applied and tested is therefore through morphological measurements. Because in development, size and shape tend to change through growth, cases of heterochrony have been documented through a quantitative analysis of size and shape, called allometry (Gould, 1977; Klingenberg, 1998; Webster and Zelditch, 2005; Box and Glover, 2010). This resulted in detailed descriptions of quantitative variation of morphology and inferences of heterochrony. Heterochrony is not limited to morphological observations though and a developmental viewpoint of the concept was elaborated in Raff and Wray (1989). More recently, Smith (2001) untangled the different historical meanings of the term heterochrony by recognizing two identifiable types: "growth heterochrony," following Gould, and "sequence heterochrony," more in line with the original usage of Haeckel and de Beer that focuses on the relative timing of developmental events. Here we wish to mainly consider the heterochronic morphological consequences of certain developmental control genes that can also be viewed as heterochronic. Such a direct link between a heterochronic underlying mechanistic process and a morphological result can, in our view, contribute to the testability of putative morphological cases of heterochrony in either mutants or evolutionary examples. Therefore, we aim to provide the term heterochrony with a clear molecular basis, without aiming to limit or redefine its meaning.

\section{THE RELATION OF HETEROCHRONY TO OTHER MODIFICATIONS OF DEVELOPMENT}

At first, it appears easy to contrast heterochrony to other modifications that can occur in the evolution of development. Heterotopy for instance, is defined as a developmental process affected in location, while heterochrony is a process affected in time. However, a shift in timing of development can also result in a change in location. For instance a petal primordium could develop later than usual and as a consequence also shift in position. This illustrates that strictly using morphological observations, it is difficult to distinguish modifications in ontogeny. In previous discussions of heterochrony in plants, there was no mention yet of heterochronic genes or a pathway identified. However, now that a pathway has been identified, by investigating the mechanistic (molecular) process behind a morphological change, a distinction could be made between heterochrony and heterotopy based on the underlying genes affected. A further problem is how to distinguish heterochrony and heterotopy from homeosis, another important category in evolution of development which entails the transformation in evolution of the identity of an organ. We would argue that homeosis can be the result of both heterochrony and heterotopy. For instance a sepal to petal transformation can result from a spatial shift of the petal identity program, but it could also result from a heterochronic shift.

One explicit criticism is that heterochrony is unable to explain the origin of new structures in evolution, as only a shift in time of an existing process is meant by the term (Horder, 2013). However, the same criticism could be voiced against homeosis and heterotopy and relates more to the effect of the shift being dynamic or static (Webster and Zelditch, 2005). When dynamic, a modification in size, shape, or identity of the structure occurs during the shift, while when static the structure is only repositioned in time or location.

\section{TYPES OF HETEROCHRONY}

Several attempts have been made to classify types of morphological heterochrony based on the possible outcomes of allometric 
studies and the two major types have been termed paedomorphosis and peramorphosis. Paedomorphosis results in juvenile structures in adult stages while peramorphosis results in the extended development of structures. Either form can be explained by three developmental causes, as proposed in the typology of Alberch et al. (1979). The causal subdivisions rely on the analogy of development being linear (Figure 2A). This "developmental line" is determined by (1) a point of onset or the start of development, (2) a rate of development represented by the local slope of the line, and (3) an offset of development (McNamara, 2012).

We illustrate this typology for simple and hypothetical cases of heterochrony in plants as shown in Figure 2B. While depicting development would in principle require several growth stages for every example, for plants it suffices to draw only the adult stage because these stages are retained in the adult plant (Figure 2B). When underdevelopment in paedomorphosis is caused by a delay in onset, this is called post-displacement (Figure 2B, b). So far no such case has been described in plants ( $\mathrm{Li}$ and Johnston, 2000), but a hypothetical example could be the development of more cotyledons, with a delay of the onset of the juvenile phase as a result. The term neoteny is used when paedomorphosis is the result of a slower developmental rate. For example, fewer leaves could develop as illustrated in (Figure 2B, c). As an extreme example, the entire adult plant could retain juvenile characters, such as in species of Lemnaceae. A third paedomorphic subtype, progenesis, is used when offset occurs earlier. One example could be the omission of a terminal developmental stage like bract development in Figure 2B, d. Contrary to paedomorphosis, characters develop "beyond" the ancestor in peramorphosis. When onset of developmental processes is earlier, we use the term pre-displacement (Figure 2B, e). For example, juvenile leaves develop immediately, without developing cotyledons first. When developmental rate is faster we use acceleration (Figure 2B, f). A result of an acceleration could be the development of more organs and finally the contraction of internodes between floral organs in the flower. Finally in hypermorphosis, development beyond the offset point, can result in the development of additional organs, such as bracts (Figure 2B, g).

It becomes more difficult when one wants to apply this terminology to more realistic examples (Figure 2C). For instance, neoteny according to Takhtajan (1976) could explain the origin of the folded carpel (Figure 2C, a). Ancestral carpels would origin from unfolded leaf-like structures which had to pass through a juvenile stage of unfolding. The derived folded carpels thus resemble the juvenile folded stage. But also the origin of sepals from bracts has been hypothesized to be neotenic (Arber, 1937; Takhtajan, 1976). Sepals can be interpreted as small leaves and seem juvenile in a way (Figure 2C, b). Alternatively, we think the latter could be named progenesis, because development of bracts stops earlier with a smaller leaf as a result. Cleistogamous flowers have been a classic example of heterochrony (Figure 2C, c). Where Gould (1988) used to believe that the cleistogamous flower was a paedomorphic "progenetic dwarf" version of the chasmogamous flower (progenesis), several studies showed that different heterochronic processes are involved in the resulting precocious, but unopened and smaller, flower (Mayers and Lord, 1983a,b; Li and Johnston, 2000; Porras and Muñoz, 2000). In cleistogamous flowers of Viola odorata for example, pollen maturation initiates earlier compared to the ancestral chasmogamous flower (predisplacement). But not only the early onset of meiotic processes will lead to precocious flowers, an increased leaf initiation rate and flower formation (acceleration) and a repressed cell expansion (progenesis) will contribute to the final phenotype. Finally, enlarged sepals have been interpreted as vegetative characters displaced into reproductive development (Figure 2C, d). A good example is the inflated calyx of Physalis species after fertilization. This could be interpreted as hypermorphosis, as the organ develops beyond its normal growth and the vegetative character extends into the reproductive phase.

From these examples it becomes clear that identifying the exact type of heterochronic evolution in more realistic examples is often difficult and it can be expected that more than one type is involved in many cases of heterochronic evolution ( $\mathrm{Li}$ and Johnston, 2000). The identified type of heterochrony can also depend on the chosen point of reference. In animals, the most often chosen point of reference is sexual maturity. In plants, several other points of reference have been used like the initiation of primordia as an onset, or anthesis as offset (Li and Johnston, 2000; Box and Glover, 2010).

\section{A HETEROCHRONIC PATHWAY IN FLOWERING PLANTS}

While extensive literature is available on heterochrony, its definition and typology, at least for plants this does not take into account a now known mechanistic basis of developmental timing. In this paragraph, we provide an updated brief introduction to a basic mechanism of developmental timing, which is extensively reviewed elsewhere (Chuck et al., 2009; Huijser and Schmid, 2011; Zhu and Helliwell, 2011; Schwab, 2012; Yamaguchi and Abe, 2012). What we denote here as one recently discovered "heterochronic pathway" is more specifically the sequential and antagonistic function of two microRNA's, their upstream regulators and downstream effectors or targets.

It has been established that two microRNA's, miR156 and miR172, act as the main players in the regulation of developmental timing in flowering plants (Chuck et al., 2007a,b; Wang et al., 2009; Wu et al., 2009). In early stages of development, miR156 levels are high and they decrease during plant development, while miR172 shows the opposite pattern. These microRNA's contribute to both the juvenile-adult phase transition and the transition to flowering through their sequential and antagonistic actions (Wu et al., 2009). miR156 represses targets of the SQUAMOSA PROMOTOR BINDING PROTEIN-LIKE (SPL) gene family and maintains juvenile features of the plant (Schwab etal., 2005). When miR156 levels decline, the SPL proteins increase and will activate miR172, activate flowering genes, and induce adult leaf features (the functional evolution of SPL genes is reviewed in Preston and Hileman, 2013). miR172 targets 6 members of the AP2-like transcription factor family in Arabidopsis (Aukerman and Sakai, 2003). During the stages when miR172 levels are increasing, the APETALA2-like (AP2-like) genes are progressively silenced and adult leaf traits and flowering is induced. 


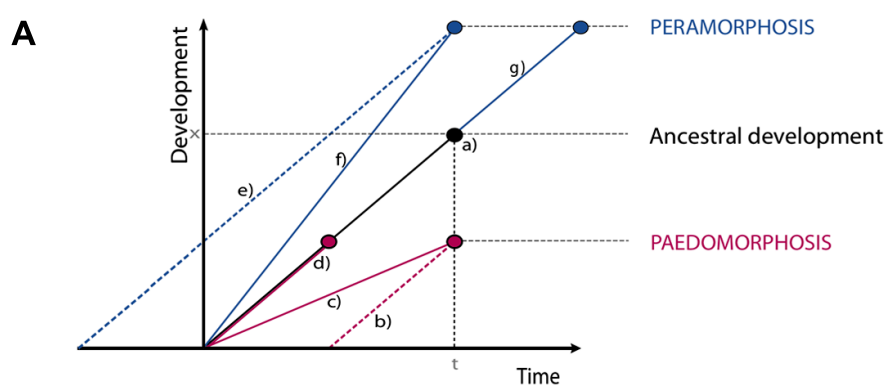

B

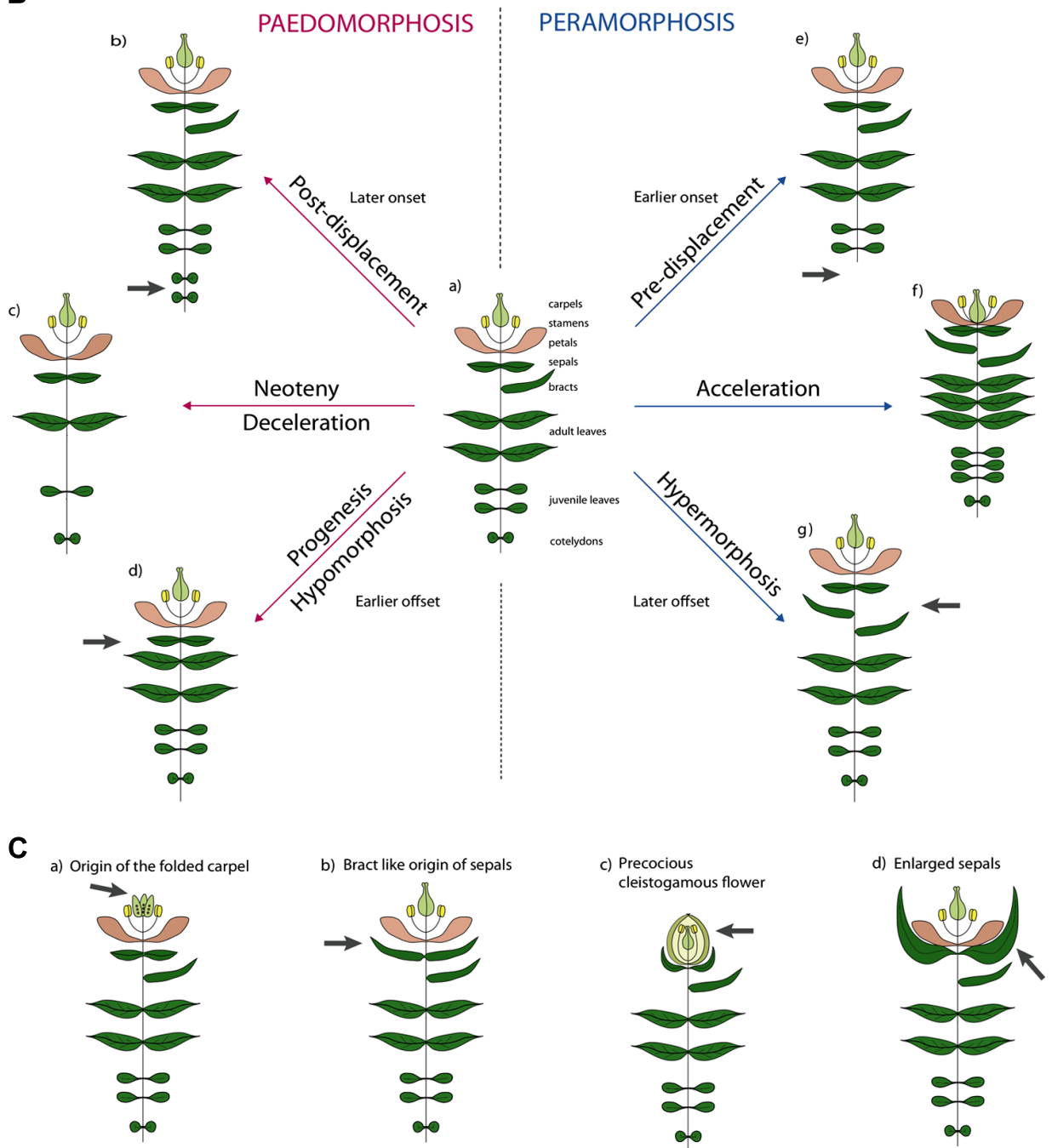

FIGURE 2 | Illustrative examples of types of heterochronic evolution. (A) Schematic overview of the different types of heterochrony. Developmental time is the time span required to reach a certain developmental stage. In normal ancestral development (a) an organism requires time span $t$ to reach development stage $x$. In Paedomorphosis development is reduced. Depending on the cause three subtypes can be distinguished. Delayed onset is the cause in post-displacement (b). In neoteny (c) development rate is slowed down. In progenesis (d) the normal time span is shortened, development will stop prematurely. In Peramorphosis an extended level of development is achieved. Again, we distinguish three subtypes. In pre-displacement $(\mathbf{e})$ an earlier onset will result in a prolonged time span of development or in early maturation. In acceleration (f) developmental rate is increased. Finally, in hypermorphosis $(\mathbf{g})$ development is continued after normal offset. (B) Hypothetical examples of heterochrony. Figure (a) shows a reference plant with different types of plant organs. Peramorphic develop "beyond" this, while paedomorphic plants retain juvenile features. In post-displacement (b), onset is later and an additional pair of cotyledons develops, in pre-displacement (e), onset is later and no cotyledons develop. In neoteny, less organs develop with larger internodes (c), while in acceleration (f), more organs develop with shorter internodes. In progenesis (d), offset is earlier and no bract develop, while in hypermorphosis $\mathbf{( g )}$, offset is later and additional bracts develop. (C) Examples of heterochrony taken from the literature. See text for explanation. 
Even though much progress is made in understanding the regulation of phase transitions through microRNA's and their downstream effectors, the upstream molecular mechanisms are just starting to be understood only in Arabidopsis thaliana. Recently it was shown that sugars control the miR156 age-dependent decrease (Proveniers, 2013; Yang et al., 2013; Yu et al., 2013). When growing older, the plant accumulates sugar through increasing photosynthesis activity. Sugar in turn represses miR156 expression at the transcriptional and post-transcriptional level, causing miR156 to decrease (Yang et al., 2013; Yu et al., 2013). miR172 levels can also be influenced by other environmental factors. SHORT VEGETATIVE PHASE (SVP) binds directly to the pri-miR172a promoter and represses transcription at low ambient temperatures (Cho et al., 2012a). FCA (a RNA binding protein) on the other hand stimulates pri-miR172 processing at high ambient temperatures (Jung etal., 2012). Both genes are thus involved in the ambient temperature-dependent regulation of $m i R 172$ and will delay flowering when ambient temperatures are low. These mechanisms correspond to the increase in $m i R 172$ abundance at $23^{\circ} \mathrm{C} \mathrm{com-}$ pared to $16^{\circ} \mathrm{C}$ (Lee et al., 2010). In contrast, $m i R 156$ is upregulated at $16^{\circ} \mathrm{C}$ compared to $23^{\circ} \mathrm{C}$, but the molecular mechanism causing this has not been identified (Lee et al., 2010). Photoperiod, and more precisely long days, seems to upregulate miR172 levels as well. In gigantea ( $g i$ ) mutants miR172 was decreased, while there was no effect in constans mutants. GI probably executes this function by affecting miR172 maturation rather than transcription (Jung et al., 2007). Other environmental factors like salinity or UV-stresses and phosphate starvation can cause similar changes in mature miR156 and miR172 levels, but underlying mechanisms remain unresolved (Zhou et al., 2007; Hsieh et al., 2009; Gu et al., 2010).

Developmental timing has been extensively studied from the viewpoint of the juvenile-adult transition and the transition to flowering. Yet, miR172 and its target AP2 have important regulatory roles in flower development as well. First of all a negative feedback regulation exists between miR172 and AP2 in the flower to help establish floral organ identity (Grigorova et al., 2011; Wollmann etal., 2010). In the two inner whorls miR172 represses AP2 to guarantee stamen and carpel development (Aukerman and Sakai, 2003; Chen, 2004), while in the two outer whorls AP2 together with co-repressors SEUSS and LEUNIG represses miR172 by binding directly to the miR172 promoter sequence in order to develop sepals and petals (Grigorova et al., 2011). In addition AP2, together with TOPLESS and HDA19, also functions as a repressor in the regulation of the outer boundaries of expression of organ identity genes belonging to B, C, and E classes (Krogan et al., 2012). Finally, in order to establish floral determinacy, miR172 and AGAMOUS cooperate to downregulate WUSCHEL expression which is enhanced by AP2. A recently discovered player, POWERDRESS, will promote transcription of $\operatorname{miR} 172 a, b$, and $c$ genes in order to confer this floral determinacy by impeding AP2 accumulation (Yumul et al., 2013).

In conclusion we can say that aside from the well known downstream targets, more and more upstream regulators are being identified. All these genes can thus influence the heterochronic pathway by regulating the microRNA expression levels and can be considered heterochronic genes.

\section{ORIGIN AND EVOLUTION OF HETEROCHRONIC GENE FUNCTIONS IN LAND PLANTS}

The pathway described above has been best studied in Arabidopsis thaliana and maize, and its basic function in controlling developmental timing is likely to be conserved in flowering plants, gymnosperms, and to some extent in ferns (Axtell and Bartel, 2005; Shigyo et al., 2006; Axtell et al., 2007; Floyd and Bowman, 2007; Huijser and Schmid, 2011). In addition the interaction of miR156 with its targets is probably also conserved in mosses (Arazi et al., 2005; Axtell et al., 2007). However, in the moss model system Physcomitrella patens, miR156 promotes the development of leafy gametophores, suggesting that its function in flowering plant sporophytes evolved from an opposite function in moss gametophytes (Cho et al., 2012b). Much about its functional origins in sporophyte development may be learned from studying this microRNA in lycopods, ferns, and gymnosperms. Yet precisely for these plant lineages researchers are confronted with strong methodological limitations, such as the inability to genetically modify species.

The interaction of miR172 and its targets probably originated after the divergence of mosses, lycopods (Floyd and Bowman, 2007), and probably ferns. MIR172 like sequences may be present in the moss Physcomitrella genome and the water fern Marsilea (unpublished genbank data) as evident from bioinformatic sequence analysis, but their expression levels are extremely low or absent, suggesting that these sequences are not functional in mosses and probably in ferns (Fattash et al., 2007; Axtell and Bowman, 2008). The biological significance of these sequences therefore remains unclear. Also our own cloning efforts did not result in miR172 sequences from selected fern species. This is in contrast to the miR172 binding site in an APETALA2-like putative target which is present in ferns but not in lycopods. In the AP2-like sequences of the lycopod Selaginella, no miR172 binding site is present (Floyd and Bowman, 2007).

While little evidence is available for the presence of miR172 in ferns, in Ceratopteris thalictroides, a putative miR172 target sequence has been cloned (Axtell and Bartel, 2005). In the absence of a convincing sequence or expression pattern for a mature miR172 microRNA in ferns, an open question is whether the cloned APETALA2-like genes with miR172 binding site is progressively downregulated in Ceratopteris development. To investigate whether this APETALA2-like putative target displays an expression decrease during sporophyte development in ferns, we investigated its expression using qRT-PCR in a developmental time series of the fern Ceratopteris richardii sporophyte (Figure 3). We indeed observed a decrease in expression levels with an increased developmental age. Interestingly, we did not find expression to be detectable in the Ceratopteris gametophyte, suggesting that this target gene only functions in sporophyte development. These data add to the idea that developmental timing is regulated by AP2-like genes in ferns. The data together suggest that the binding site in $A P 2$ likely evolved before the origin of the cognate microRNA, but that AP2-like genes already are involved in developmental timing in ferns. Because of the likely absence of $m i R 172$ in ferns, an alternative mechanism may be responsible for the progressive down regulation of $A P 2$. 


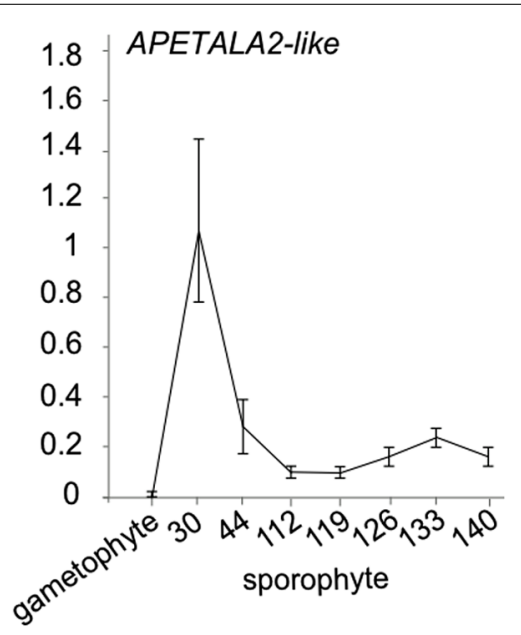

FIGURE 3 | APETALA2-like expression in Ceratopteris richardii developmental time series. $\mathrm{QRT}$ TPCR of a putative miR172 target APETALA2-like gene with a putative miR172 binding site in gametophytes and sporophyte stages of development. Error bars are standard deviation of three biological replicates.

\section{TIME-DEPENDENT GRADED EXPRESSION OF HETEROCHRONIC GENES AND PLANT ORGAN IDENTITY}

A central idea behind heterochrony in plants is that a graded signal exists that changes with time and establishes the identity of the plant organs. In vegetative development this graded signal has been shown for different types of leaves and is referred to as heteroblasty (Allsopp, 1967; Kerstetter and Poethig, 1998; Poethig, 2010). In maize, Arabidopsis and poplar, it has been shown that transformation of leaf type can be established by manipulating expression levels of microRNA156 (Wu and Poethig, 2006; Chuck et al., 2007a; Wu et al., 2009; Wang et al., 2011). This suggests that the relative expression level of microRNA's determine the age of the shoot apex that develops leaf primordia (Schwab, 2012). In the only molecular study that includes multiple species, Wang et al. (2011) also show that juvenile and adult leaf type correlate with these expression levels in Hedera, Acacia, and Quercus, which are classic examples of heteroblasty.

Even von Goethe already noted not only that the different vegetative plant organs appeared remarkably similar to each-other, as if they metamorphosed from one type into another. He also applied the same idea to the reproductive organs (Figure 1). Only miR172 levels have been analyzed in detail during flower development of Arabidopsis thaliana (Wollmann et al., 2010). Throughout flower development they showed a graded expression pattern from the outer whorls to the inner whorls. miR172 expression was higher in the shoot apical meristem than in early flower primordia and in successive stages of flower development miR172 became increasingly restricted to the center. In the latest stages expression was only detected in developing ovules. This suggests that indeed, also for floral organs a different relative expression level of at least $m i R 172$ characterizes the floral organs. If indeed, $m i R 172$ is heterochronically regulating organ identity in the flower, we would expect that partial knock-down would result in petals transforming into sepals, stamens into petals, and carpels into stamens.
Complementary, constitutive expression would result in upward identity shifts along the floral axis. Partially consistent with this prediction, knock-down of miR172 in stamens results in a partial transformation to petals in Arabidopsis (Wollmann et al., 2010). A problem with miR172 knock-down is that one is not necessarily able to generate slightly different levels that result in predictable transformations (Todesco et al., 2010). For this, the genetic analysis of the different miR172 genes will be illuminating. While miR172 ectopic expression in Nicotiana benthamiana results in the transformation of sepals into petals (Mlotshwa et al., 2006), miR172 ectopic expression in Arabidopsis results in sepals transformed into carpels and the absence of petals, strongly resembling the ap2 mutant (Chen, 2004). It could be that in Arabidopsis, constitutive expression under the $35 \mathrm{~S}$ promoter attains too strong level to obtain the expected series of organ identity transformations dependent on the expression level of miR172. Consistent with this idea is that ectopic ovules also develop on the leaves in these plants and entire gynoecia in the axil of leaves (Aukerman and Sakai, 2003).

\section{A HETEROCHRONIC INTERPRETATION OF APETALA2 GENE FUNCTIONS}

As APETALA2-like genes are under the direct control of miR172, their functions can also be interpreted as heterochronic. While originally, Arabidopsis APETALA2 function was interpreted as Afunction in the ABC model (Coen and Meyerowitz, 1991), multiple functions for APETALA2-like genes can now be distinguished. Two functions are involved in the timing of identity transitions, either from the shoot apical meristem into a flower meristem or in the identity transitions of floral organ primordia. A third function is in floral determinacy, the end or offset of development.

A first function of APETALA2 is in timing the specification of the floral meristem by repressing vegetative characteristics from flowers. This function is clear from the phenotypes in several species in which flowers acquire vegetative characters such as the development of bracts and supernumerary sepals (Litt, 2007). This is the case for Arabidopsis ap2 alleles, in which sepals are often transformed into bracts or leaf-like structures (Bowman et al., 1989). Similar phenotypes have been observed for Antirrhinum lip1/lip2 mutants and also in the rice homolog supernumerary bracts and the maize double mutant indeterminate spikelet $1 /$ sister of indeterminate spikelet 1 (Keck et al., 2003; Lee et al., 2007; Chuck et al., 2008). The heterochronic interpretation of these phenotypes is that because of a delayed transition from inflorescence meristem to floral meristem supernumerary bract-like organs develop.

A second function is in timing the identity of the floral organs. In the $\mathrm{ABC}$ model, it was proposed that a floral Afunction exists that acts to repress C-function from the outer floral organ whorls and contributes to the establishment of sepal and petal identity. Recent findings in Arabidopsis show that the repressive function of APETALA2 is more general and that the outer boundaries of B-function (APETALA3 and PISTILLATA), E-function (SEPALLATA3), and C-function are marked by APETALA2 (Krogan et al., 2012). The classic ABC model with homeotic functions may thus alternatively be viewed as a combination of heterochronic and heterotopic functions to specify floral 
organ identity. Heterotopic functions would involve only B- and C-function added onto a ground state of floral meristem identity (Litt, 2007).

APETALA2 mutants in different species also show other heterochronic phenotypes. A mutant with a weaker phenotype in a maize AP2-like gene is glossy15, which develops adult characteristics in juvenile leaves (Lauter et al., 2005). In barley, the cleistogamy1 mutant was positionally cloned and identified as an AP2-like gene (Nair et al., 2010) which is interesting considering that cleistogamous flowers are a classic example of heterochrony (Lord and Hill, 1987).

\section{DETECTING HETEROCHRONY THROUGH HETEROCHRONIC PATHWAY GENES}

Previous review literature on heterochrony in plants (Lord and Hill, 1987; Li and Johnston, 2000; Box and Glover, 2010), discusses the concept of heterochrony in terms of morphological changes in development and not in terms of heterochronic genes. A problem with a morphological definition of heterochrony is that it can become too broadly applicable. Any type of growth or induction at every scale has a time aspect attached to it and such heterochronies would likely have many different underlying causes. This would contribute little to the use of the term heterochrony. Examples of proposed heterochronic evolution may then seem naive or the application of the term does not appear useful anymore. For instance, it is possible to use the term progenesis for a population of Arabidopsis thaliana, either mutant or natural, that flowers early. The question is whether applying such a term contributes much to our understanding of evolution. It soon becomes possible to call all evolution of development heterochrony when the term is not more strictly applied. However, classic examples of heterochrony that stand a more rigorous test may be present in the literature (see below). The question may thus become how to investigate putative cases using current methods. While flowering time per se may appear to be a phenotype straightforwardly interpreted as heterochronic, as we argue here, investigating whether a heterochronic gene pathway is affected would help to direct conclusions on heterochronic evolution ( $\mathrm{Li}$ and Johnston, 2000).

We propose that cases of heterochrony could be confirmed by three criteria. First, a member of a "heterochronic pathway" is affected. Second, this results in what can be interpreted as a heterochronic shift in the evolution of development. Third, phylogenetic evidence is available for the heterochronic shift to have occurred in a meaningful window of evolutionary time. This will usually mean that an ancestral character state can be inferred or is available, as is wild-type in the case of mutants. Such a more narrow definition brings along clearer ways to test cases of heterochronic evolution which is otherwise not possible. Cases of heterochronic evolution or heterochronic mutations can be investigated by monitoring members of the known heterochronic pathway in development. If their action has modified in comparison to the ancestral form or in comparison to the wild-type, this can be taken as evidence for heterochrony. As is often the case in evolution and development, it is difficult to pinpoint exactly which gene has been affected in evolution. An initial approach to this problem is to investigate whether one of the microRNA's or one of their targets show a changed expression pattern in development. More rigorously, the candidate gene can be further characterized using transgenic or genetic approaches. Thoroughly investigating heterochronic evolution at the molecular level should be helpful in correctly identifying the type of heterochrony and determining whether onset, rate or offset of developmental time has changed. In addition, the relative frequency of this heterochrony versus other modes of developmental evolution can be investigated and the types of morphological consequences can be described.

\section{TWO HETEROCHRONIC MUTANTS: Antirrhinum incomposita AND choripetala}

We illustrate these above points by investigating the Antirrhinum majus incomposita (inco) and choripetala (cho) mutants. The inco mutant has been characterized both morphologically and genetically in Masiero et al. (2004) and Wilkinson et al. (2000). While inco is affected in an ortholog of the Arabidopsis MADS-box gene SVP, the molecular basis of the cho phenotype remains unresolved. Inco flowers characteristically develop prophylls or bract-like structures at the base of their flowers, while these are absent from wild-type Antirrhinum flowers (Figure 4A). Some flowers also display a petaloid sepal phenotype, which inco has in common with cho (Figures 4B,C). The petaloid sepal phenotype in inco is strongly enhanced in a cho background, suggesting that INCO and $\mathrm{CHO}$ are functionally related in controlling sepal identity. At least for cho it has been shown that the petaloid sepals show ectopic B-class gene expression (Wilkinson et al., 2000).

From a morphological point of view, the ontogeny of inco and cho mutants has been compared to wild-type flower development using scanning electron microscopy. Such an analysis has the potential to reveal shifts in the relative timing of organ development, or heterochronies. Indeed for inco, the initiation of the lateral sepals is delayed and the primordia are displaced toward the center of the flower primordium. Probably as a consequence, the lateral sepals become fused and petaloid in inco (Masiero et al., 2004). Comparative ontogeny of wild-type and cho revealed that the sepals are narrower at initiation and their growth rate is reduced. This also makes cho interesting from a heterochronic point of view (Wilkinson et al., 2000).

To understand whether the heterochronic morphologies of inco and cho can be explained by modifications to the regulation of heterochronic pathway genes, we investigated in both wild-type and cho biological replicates the expression patterns of mature microRNA's 156 and 172 using stem-loop qRT-PCR relative to the housekeeping gene actin. While we retrieve the expected expression pattern in wild-type plants (Figure 4D), remarkably in cho and more strongly in inco miR172 expression is notably higher late in adult development only to strongly decrease rather than increase when flowers develop (Figures 4E,F). These expression patterns illustrate that modifications in developmental timing can be complex. It would also be difficult to classify cho as pre-displaced or neotenic because of the combination of rate effects. Furthermore, if the phenotypes can be (partially) explained by this changed expression pattern, our observations contribute to the notion that heterochronic phenotypes can be diverse. 

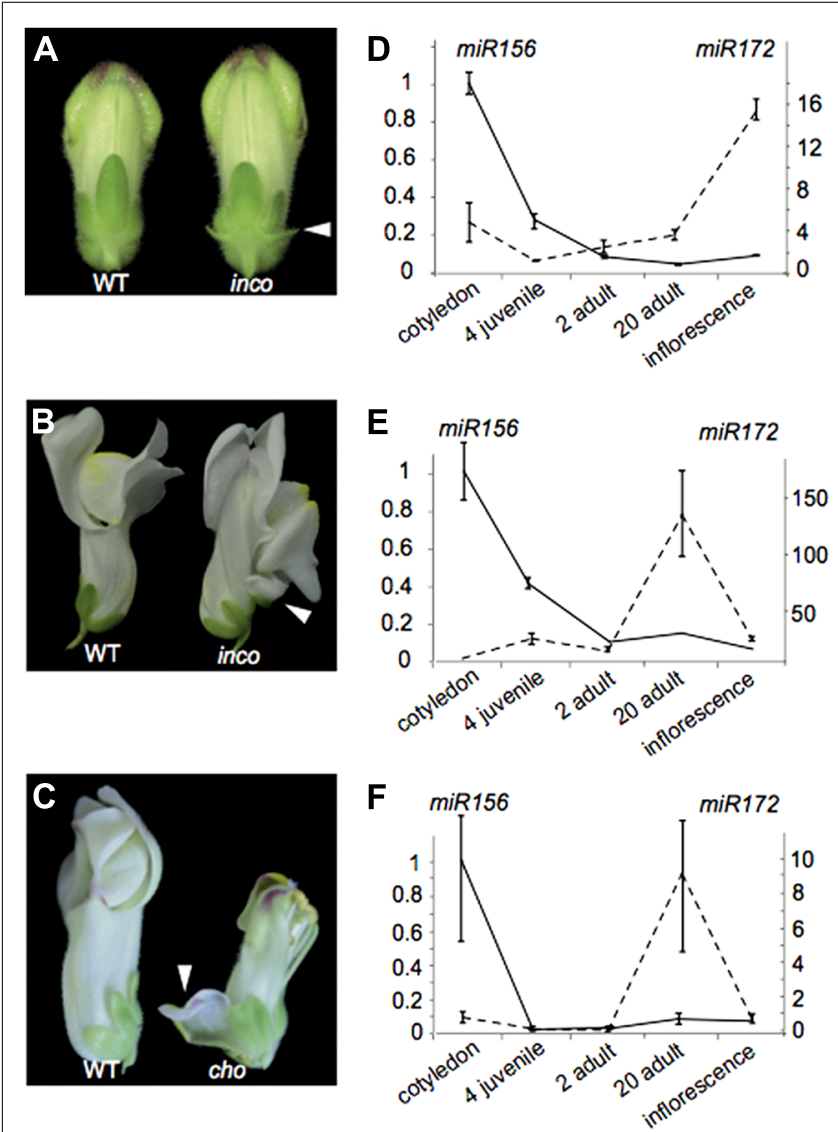

FIGURE 4 |The heterochronic Antirrhinum mutant choripetala. (A) In incomposita, prophylls develop which are absent in wild-type Antirrhinum flowers. (B) Inco also occasionally develops petaloid sepals. (C) Petaloid sepals and an unfused corolla can also be observed in choripetala. (D) The expression pattern of miR156 (left axis) and miR172 (right axis) in Antirrhinum is similar to what has been observed for wild-type Arabidopsis and other species. Both in inco (E) and in cho (F), an early increase in miR172 can be observed late in adult development and lower expression levels are present in inflorescence tissue. Error bars represent standard errors of three technical replicates. A second biological replicate gave similar results.

\section{PUTATIVE CASES OF HETEROCHRONIC EVOLUTION IN PLANTS}

While in the previous paragraphs we provided a heterochronic interpretation of mutant phenotypes, a number of putative classic cases of heterochronic evolution can be investigated now that a heterochronic pathway has been elucidated. The question is whether the pathway is affected in these instances and how?

A series of studies in evolution and development has tried to correlate expression of B-function genes to petal identity in sepals or bracts. These studies inconsistently did, or did not observe ectopic expression of B-function (Litt and Kramer, 2010; Ronse De Craene and Brockington, 2013). It will be interesting to reinvestigate some of these studies in light of the idea that APETALA2 is able to repress floral homeotic functions from the outer whorls as shown in Arabidopsis (Krogan et al., 2012). In the two cases in core eudicots we investigated, Davidia involucrata and Impatiens hawkeri, there was no clear indication of maintained heterotopic B-function expression (Geuten et al., 2006; Vekemans et al., 2012). If the causative gene indeed appears to be APETALA2, most of this type of morphological diversity may be heterochronic in nature rather than heterotopic as was previously proposed (Albert et al., 1998).

Heterotopic expression of showy characters outside the flower usually is also accompanied with modifications in organ shape and size. In some of these cases, ectopic expression of SVP has been implicated. The original observations derive from the maize Tunicate mutation (Han et al., 2012; Wingen et al., 2012). One of the best characterized naturally occurring cases of this modification in evolution is the inflated calyx syndrome in Physalis for which it was demonstrated that a homolog of SVP is heterotopically (or heterochronically?) expressed (He and Saedler, 2005). A link with either the microRNA's or APETALA2 expression has not been made thus far and awaits investigation. Yet such a link would not be too surprising as SVP is known to regulate miR172 in Arabidopsis (Cho et al., 2012a).

The occurrence of cleistogamy has also been considered as heterochronic in the sense that the cleistogamous flowers relative to their chasmogamous flowers appear to end development prematurely (Lord and Hill, 1987). An extensively studied example is the one of V. odorata (Mayers and Lord, 1983a,b). This violet develops cleistogamous flowers in response to long days and chasmogamous flowers in response to short days. Similar to the effect in flowers is the change in shoot identity in relation to changes in photoperiod that can be observed in the leaves. Small cleistogamous flowers develop in the axil of leaves with long petioles, while chasmogamous flowers develop in the axil of small leaves with short petioles. $V$. odorata thus displays heterochronic variation in both flower and leaf development.

An example from gymnosperms is the spruce acrocona mutant, which develops reproductive cones with vegetative characters (Carlsbecker et al., 2013; Ruelens and Geuten, 2013). A final classic example of heterochronic variation in leaf shape can be found in Marsilean ferns (Allsopp, 1967; Pryer and Hearn, 2009). The leaves of the genus Marsilea develop different leaf shapes depending on environmental conditions. One condition is submergence under water. These types of leaves are also present in the evolutionary related genera, Pillularia and Regnellidium. Even more reduced leaves can be found in the related genera Azolla and Salvinia. Molecular data on these last two classic examples of heterochrony is not available yet, but could clarify if and how the heterochronic pathway can evolve.

\section{THE IMPORTANCE AND APPLICABILITY OF HETEROCHRONY}

Heterochrony in animal evolution and development has been recognized as the major evolutionary mechanism contributing to diversity (De Beer, 1951; Gould, 1977). In comparison to animals, the role attributed to heterochrony in the evolution of plant development is historically smaller, not necessarily reflecting the biological significance of the concept. Indeed, notable exceptions, such as Armen Takhtajan, acknowledged a major role for heterochrony in plant evolution. Heterochrony by these proponents has been used to explain major, still outstanding questions in botany, such as the neotenic origin of the flower (Takhtajan, 1976). 
We propose that the molecular study of putative cases of heterochrony will assist in assessing the relative frequency of this type of developmental evolution in comparison to other types.

There are obvious and previously noted methodological difficulties when applying the idea of heterochrony to plants. The open development of plants was originally thought to be more difficult to study from a heterochrony point of view (De Beer, 1951). As plant development initiates in closed buds, the primordia are not easily visualized in a dynamic manner. Therefore, measuring the rate of development usually is indirect, through the use of an average developmental rate over a prolonged period of time. For instance the counting of leaves that developed in a certain time. For flower development, most studies lack data on either growth rate or relative timing of events. Average developmental rate cannot be measured and needs to be estimated from comparative floral ontogenetic work. While difficult, several of these examples have been reported though not necessarily recognized as heterochrony, such as the incomposita and choripetala mutants described above (Wilkinson et al., 2000; Masiero et al., 2004). A reason why heterochrony in leaf development (heteroblasty) is thought to be difficult to study is that many plants lack clear morphological markers for the transition from the juvenile to the adult and sexually mature stage. However, now that clear molecular markers are available to study the transition from the juvenile to adult phases in development, this difficulty can be overcome.

We would argue that plants, because they retain previous developmental stages in the adult form, are excellent models to study heterochrony. Even now, our current thinking about plant morphology could be named "heterochronic." For example the idea of a carpel as essentially a folded young leaf reveals this (Arber, 1937; Takhtajan, 1976).

\section{MATERIALS AND METHODS}

C-fern (Ceratopteris) spores were obtained from Carolina Biologicals (NC, USA). Antirrhinum majus choripetala and wild-type seeds were obtained from IPTK Gatersleben. For Ceratopteris richardii, spores were germinated in liquid (for gametophytes) or on solid (for sporophytes) Basic C-fern medium (NC, USA) in a Conviron Adaptis growth cabinet at $25^{\circ} \mathrm{C}$ under $200 \mu \mathrm{mol}$ photons per meter squared per second (photosynthetic photon flux density PPFD) of cool white light in a 16 h light, 8 h dark

\section{REFERENCES}

Alberch, P., Gould, S. J., Oster, G. F., and Wake, D. B. (1979). Size and shape in ontogeny and phylogeny. Paleobiology 5, 296-317.

Albert, V. A., Gustafsson, M., and Di Laurenzio, L. (1998). "Ontogenetic systematics, molecular developmental genetics, and the angiosperm petal," in Molecular Systematics of Plants II, eds D. E. Soltis, P. S. Soltis, and J. J. Doyle (Dordrecht: Kluwer Academic Publishers), 349-374

Allsopp, A. (1967). Heteroblastic development in vascular plants. Adv. Morphog. 6, 127-171.

Arazi, T., Talmor-Neiman, M., Stav, R., Riese, M., Huijser, P., and
Baulcombe, D. C. (2005). Cloning and characterization of micro-RNA's from moss. Plant J. 43, 837848. doi: 10.1111/j.1365-313X.2005. 02499.x

Arber, A. (1937). The interpretation of the flower: a study of some aspects of morphological thought. Biol. Rev. 12, 157-184. doi: 10.1111/j.1469185X.1937.tb01227.x

Aukerman, M. J., and Sakai, H. (2003). Regulation of flowering time and floral organ identity by a MicroRNA and its APETALA2-like target genes. Plant Cell 15, 2730-2741. doi: 10.1105/tpc.016238

Axtell, M. J., and Bartel, D. P. (2005). Antiquity of microRNA's and their

daily cycle. To sample gametophytes, spores were germinated in an erlenmeyer and harvested 10 days after inoculation by centrifugation. Sporophytes were germinated in Magenta jars and sampled in triplicates $30,44,112,119,126,133$, and 144 days after plating on solid medium. Antirrhinum wild-type and incomposita seeds were germinated in the same light conditions as Ceratopteris in Magenta jars on 1/2; Murashige and Skoog medium. Seedlings were transferred to soil and placed in a growth chamber also at $25^{\circ} \mathrm{C}$ with approximately 100 PPFD of cool white light. After homogenization in liquid nitrogen, RNA was extracted using the Plant RNA Reagent (Invitrogen) for Ceratopteris and using TRIzol (Invitrogen) for Antirrhinum according to the manufacturers protocol. DNA present in the RNA prep was degraded using Turbo DNase (Inivitrogen) and degradation was confirmed by PCR amplification of actin and evaluation using agarose gel electrophoresis. DNA free RNA was then reverse transcribed using the cDNA Reverse Transcription kit (Promega) according to the manufacturers procedures. Before using the cDNA for $\mathrm{qRT}$-PCR, whether the CDNA was amplifiable was tested using regular PCR amplification of actin.

Expression analysis in Ceratopteris was performed using qRTPCR and normalized relative to actin. Primers for APETALA2 expression were $5^{\prime}$-CAGCATCATCAGGATTCTCACATAT- $3^{\prime}$ and $5^{\prime}$-GACATGGTAGATGCGGAGCTAGT-3' and for actin $5^{\prime}$-TCCTCGGGCTGTATTTCCTAGTAT- $3^{\prime}$ and $5^{\prime}$-CCTCATCACCAACATATGCATCTT-3'. For Antirrhinum, cDNA was prepared using a combination of stem-loop and oligo-dT primers. Stem-loop primers were $5^{\prime}$-GTCGTATCCAGTGCAGGGTCCGAGGTATTCGCACTGGATACGACGTGCTC-3' and 5'-GTCGTATCCAGTGCAGGGTCCGAGGTATTCGCACTGGATACGACATGCAC- $3^{\prime}$ to amplify the mature microRNA's.

\section{ACKNOWLEDGMENTS}

We would like to thank S. Eeckhout, N. Geerts, and T. Stas for technical support and FWO and University of Leuven for financial support.

\section{CONTRIBUTIONS}

Koen Geuten conceived the ideas in the manuscript. Koen Geuten and Heleen Coenen wrote the manuscript. Experiments were performed through technical assistance.

targets in land plants. Plant Cell 17, 1658-1673. doi: $10.1105 /$ tpc. 105.032185

Axtell, M. J., and Bowman, J. L. (2008). Evolution of plant microR NAs and their targets. Trends Plant Sci. 13, 343-349. doi: 10.1016/j. tplants.2008.03.009

Axtell, M. J., Snyder, J. A., and Bartel, D. P. (2007). Common functions for diverse small RNA's from land plants. Plant Cell 19, 1750-1769. doi: 10.1105/tpc.107.051706

Bowman, J. L., Smyth, D. R., and Meyerowitz, E. M. (1989). Genes directing flower development in Arabidopsis. Plant Cell 1, 37-52.
Box, M. S., and Glover, B. J. (2010). A plant developmentalist's guide to paedomorphosis: reintroducing a classic concept to a new generation. Trends Plant Sci. 15, 241-246. doi: 10.1016/j.tplants.2010.02.004

Carlsbecker, A., Sundström, J. F., Englund, M., Uddenberg, D., Izquierdo, L., Kvarnheden, A., et al. (2013). Molecular control of normal and acrocona mutant seed cone development in Norway spruce (Picea abies) and the evolution of conifer ovule-bearing organs. New Phytol. doi: 10.1111/nph.12360 [Epub ahead of print].

Chen, X. (2004). A microRNA as a translational repressor of APETALA2 
in Arabidopsis flower development. Sci. Signal. 303, 2022

Cho, H. J., Kim, J. J., Lee, J. H., Kim, W. Jung, J. H., Park, C. M., et al. (2012a). SHORT VEGETATIVE PHASE (SVP) protein negatively regulates miR 172 transcription via direct binding to the pri-miR172a promoter in Arabidopsis. FEBS. Lett. 586, 23322337. doi: 10.1016/j.febslet.2012. 05.035

Cho, S. H., Coruh, C., and Axtell, M. J. (2012b). miR156 and miR390 Regulate tasiRNA accumulation and developmental timing in Physcomitrella patens. Plant Cell 24, 4837-4849. doi: 10.1105/tpc.112.103176

Chuck, G., Candela, H., and Hake, S. (2009). Big impacts by small RNAs in plant development. Curr. Opin. Plant Biol. 12, 81-86. doi: 10.1016/j.pbi.2008.09.008

Chuck, G., Cigan, A. M., Saeteurn, K., and Hake, S. (2007a). The heterochronic maize mutant Corngrass 1 results from overexpression of a tandem microRNA. Nat. Genet. 39, 544-549. doi: 10.1038/ng2001

Chuck, G., Meeley, R., Irish, E., Sakai, H., and Hake, S. (2007b). The maize tasselseed4 microRNA controls sex determination and meristem cell fate by targeting Tasselseed6/ indeterminate spikelet1. Nat. Genet. 39, 1517-1521. doi: 10.1038/ng. 2007.20

Chuck, G., Meeley, R., and Hake, S. (2008). Floral meristem initiation and meristem cell fate are regulated by the maize AP2 genes ids1 and sid1. Development 135, 3013-3019. doi: 10.1242/dev.024273

Coen, E. S., and Meyerowitz, E. M. (1991). The war of the whorls: genetic interactions controlling flower development. Nature 353, 31-37. doi: $10.1038 / 353031 \mathrm{a} 0$

De Beer, G. R. (1951). Embryos and Ancestors. Oxford: Clarendon Press.

Fattash, I., Voß, B., Reski, R., Hess, W., and Frank, W. (2007). Evidence for the rapid expansion of microRNA-mediated regulation in early land plant evolution. BMC Plant Biol. 7:13. doi: 10.1186/1471-22297-13

Floyd, S. K., and Bowman, J. L. (2007). The ancestral developmental tool kit of land plants. Int. J. Plant Sci. 168, 1-35. doi: 10.1086/509079

Geuten, K., Becker, A., Kaufmann, K., Caris, P., Janssens, S., Viaene, T., etal. (2006). Petaloidy and petal identity MADS-box genes in the balsaminoid genera Impatiens and Marcgravia. Plant J. 47, 501518. doi: 10.1111/j.1365-313X.2006. 02800.x
Gould, S. J. (1977). Ontogeny and Phylogeny. Cambridge: Harvard University Press.

Gould, S. J. (1988). "The uses of heterochrony," in Heterochrony in Evolution: A Multidisciplinary Approach ed. M. L. McKinney (New York: Plenum Press), 1-13.

Grigorova, B., Mara, C., Hollender, C., Sijacic, P., Chen, X. and Liu, Z. (2011). LEUNIG and SEUSS co-repressors regulate miR172 expression in Arabidopsis flowers. Development 138, 24512456. doi: 10.1242/dev.058362

Gu, M., Xu, K., Chen, A., Zhu, Y., Tang, G., and $\mathrm{Xu}, \mathrm{G}$. (2010). Expression analysis suggests potential roles of microRNAs for phosphate and arbuscular mycorrhizal signaling in Solanum lycopersicum. Physiol. Plant. 138, 226-237. doi: 10.1111/j.1399-3054.2009.01320.x

Han, J. J., Jackson, D., and Martienssen, R. (2012). Pod corn is caused by rearrangement at the Tunicate1 locus. Plant Cell 24, 2733-2744. doi: 10.1105/tpc.112.100537

He, C., and Saedler, H. (2005). Heterotopic expression of MPF2 is the key to the evolution of the Chinese lantern of Physalis, a morphological novelty in Solanaceae. Proc. Natl. Acad. Sci. USA 102, 5779-5784. doi: $10.1073 /$ pnas.0501877102

Horder, T. (2013). "Heterochrony," in eLS. Chichester: John Wiley and Sons, Ltd. doi: 10.1002/ 9780470015902.a0001778.pub3

Hsieh, L. C., Lin, S. I., Shih, A. C. C., Chen, J. W., Lin, W. Y., Tseng, C. Y., et al. (2009). Uncovering small RNAmediated responses to phosphate deficiency in Arabidopsis by deep sequencing. Plant Physiol. 151, 2120 2132. doi: 10.1104/pp.109.147280

Huijser, P., and Schmid, M. (2011). The control of developmental phase tran sitions in plants. Development 138 , 4117-4129. doi: 10.1242/dev.063511

Jung, J. H., Seo, P. J., Ahn, J. H. and Park, C. M. (2012). Arabidopsis RNA-binding protein FCA regulates microRNA172 processing in thermosensory flowering. J. Biol. Chem. 287, 16007-16016. doi: 10.1074/ jbc.M111.337485

Jung, J. H., Seo, Y. H., Seo, P. J., Reyes, J. L., Yun, J., Chua, N. H., et al. (2007). The GIGANTEA-regulated microRNA172 mediates photoperiodic flowering independent of CONSTANS in Arabidopsis. Plant Cell 19, 2736-2748. doi: 10.1105/ tpc. 107.054528

Keck, E., McSteen, P., Carpenter, R., and Coen, E. (2003). Separation of genetic functions controlling organ identity in flowers. $E M B O$ J. 22, 1058-1066. doi: 10.1093/ emboj/cdg097

Kerstetter, R. A., and Poethig, R. S. (1998). The specification of leaf identity during shoot development. Annu. Rev. Cell Dev. Biol. 14, 373-398. doi: 10.1146/annurev.cellbio.14.1.373

Klingenberg, C. P. (1998). Heterochrony and allometry: the analysis of evolutionary change in ontogeny. Biol. Rev. 73, 79-123. doi: 10.1017/ S000632319800512X

Krogan, N. T., Hogan, K., and Long, J. A. (2012). APETALA2 negatively regulates multiple floral organ identity genes in Arabidopsis by recruiting the co-repressor TOPLESS and the histone deacetylase HDA19. Development 139, 4180-4190. doi: 10.1242/dev.085407

Lauter, N., Kampani, A., Carlson, S., Goebel, M., and Moose, S P. (2005). microRNA172 downregulates glossy 15 to promote vegetative phase change in maize. Proc. Natl. Acad. Sci. U.S.A. 102, 9412-9417. doi: 10.1073/pnas.0503927102

Lee, D. Y., Lee, J., Moon, S., Park, S. Y., and An, G. (2007). The rice heterochronic gene SUPERNUMERARY BRACT regulates the transition from spikelet meristem to floral meristem. Plant J. 49, 6478. doi: 10.1111/j.1365-313X.2006 02941.x

Lee, H., Yoo, S. J., Lee, J. H., Kim, W., Yoo, S. K., Fitzgerald, H., et al. (2010). Genetic framework for flowering-time regulation by ambient temperature-responsive miRNA in Arabidopsis. Nucleic Acids Res. 38, 3081-3093. doi: 10.1093/nar/ gkp1240

Li, P., and Johnston, M. O. (2000). Heterochrony in plant evolutionary studies through the twentieth century. Bot. Rev. 66, 57-88. doi: 10.1007/ BF02857782

Litt, A. (2007). An evaluation of A-function: evidence from the APETALA1 and APETALA2 gene lineages. Int. J. Plant Sci. 168, 73-91. doi: 10.1086/509662

Litt, A., and Kramer, E. M. (2010). The ABC model and the diversification of floral organ identity. Semin Cell Dev. Biol. 21, 129-137. doi: 10.1016/j.semcdb.2009.11.019

Lord, E. M., and Hill, J. P. (1987). "Evidence for heterochrony in the evolution of plant form," in Development as an Evolutionary Process, ed. R. A. Raff and E. C. Raff (New York: Alan R. Liss), 47-70.

Masiero, S., Li, M. A., Will, I., Hartmann, U., Saedler, H., Huijser, P., et al. (2004). INCOMPOSITA a MADS-box gene controlling prophyll development and floral meristem identity in Antirrhinum. Development 131, 5981-5990. doi: 10.1242/dev.01517

Mayers, A. M., and Lord, E. M. (1983a). Comparative flower development in the cleistogamous species Viola odorata. I. A growth rate study. Am. J. Bot. 70, 1548-1555. doi: 10.2307/2443353 Mayers, A. M., and Lord, E. M. (1983b). Comparative flower development in the cleistogamous species Viola odorata. II. An organographic study. Am. J. Bot. 70, 1556-1563. doi: $10.2307 / 2443354$

McNamara, K. J. (2012). Heterochrony: the evolution of development. Evol. Edu. Outreach 5, 203-218.

Mlotshwa, S., Yang, Z., Kim, Y., and Chen, X. (2006). Floral patterning defects induced by Arabidopsis APETALA2 and microRNA172 expression in Nicotiana benthamiana. Plant Mol. Biol. 61, 781-793. doi: 10.1007/s11103-006-0049-0

Moss, E. G. (2007). Heterochronic genes and the nature of developmental time. Curr. Biol. 17, R425-R434. doi: 10.1016/j.cub.2007.03.043

Nair, S. K., Wang, N., Turuspekov, Y., Pourkheirandish, M., Sinsuwongwat, S., Chen, G., et al. (2010). Cleistogamous flowering in barley arises from the suppression of microRNA-guided HvAP2 mRNA cleavage. Proc. Natl. Acad. Sci. U.S.A. 107, 490-495. doi: 10.1073/pnas.0909097107

Poethig, R. S. (2003). Phase change and the regulation of developmental timing in plants. Science 301, 334-336. doi: $10.1126 /$ science. 1085328

Poethig, R. S. (2010). The past, present, and future of vegetative phase change. Plant Physiol. 154, 541-544. doi: 10.1104/pp.110.161620

Porras, R., and Muñoz, J. M. (2000). Cleistogamous capitulum in Centaurea melitensis (Asteraceae): heterochronic origin. Am. J. Bot. 87, 925-933. doi: 10.2307/2656991

Preston, J. C., and Hileman, L. C. (2013). Functional evolution in the plant SQUAMOSA-PROMOTER BINDING PROTEIN-LIKE (SPL) gene family. Front. Plant. Sci. 4:80. doi: 10.3389/fpls.2013.00080

Proveniers, M. (2013). Sugars speed up the circle of life. eLife 2, e00625. doi: 10.7554/eLife.00625

Pryer, K. M., and Hearn, D. J. (2009). Evolution of leaf form in marsileaceous ferns: evidence for heterochrony. Evolution 63, 498-513. doi: 10.1111/j.1558-5646.2008.00562.x

Raff, R. A., and Wray, G. A. (1989). Heterochrony: developmental mechanisms and evolutionary results. $J$. 
Evol. Biol 2, 409-434. doi: 10.1046/j. 1420-9101.1989.2060409.x

Ronse De Craene, L. P., and Brockington, S. F. (2013). Origin and evolution of petals in angiosperms. Plant Ecol. Evol. 146, 5-25. doi: 10.5091/plecevo. 2013.738

Ruelens, P., and Geuten, K. (2013). When paleontology and molecular genetics meet: a genetic context for the evolution of conifer ovuliferous scales. New Phytol. 200, 10-12. doi: $10.1111 / \mathrm{nph} .12417$

Schwab, R. (2012). “The roles of miR156 and miR172 in phase change regulation," in MicroRNAs in Plant Development and Stress Responses, ed. R. Sunkar (Berlin: Springer Berlin Heidelberg), 49-68.

Schwab, R., Palatnik, J. F., Riester, M. Schommer, C., Schmid, M., and Weigel, D. (2005). Specific effects of microRNAs on the plant transcriptome. Dev. Cell 8, 517-527. doi: 10.1016/j.devcel.2005.01.018

Shigyo, M., Hasebe, M., and Ito, M. (2006). Molecular evolution of the AP2 subfamily. Gene 366, 256-265. doi: 10.1016/j.gene.2005.08.009

Slack, F., and Ruvkun, G. (1998). Heterochronic genes in development and evolution. Biol. Bull. 195, 375-376. doi: $10.2307 / 1543152$

Slack, F., and Ruvkun, G. (1997). Temporal pattern formation by heterochronic genes. Annu. Rev. Genet. 31, 611-634. doi: 10.1146/annurev.genet.31.1.611

Smith, K. (2001). Heterochrony revisited: the evolution of developmental sequences. Biol. J. Linn. Soc. 73, 169-186. doi: 10.1111/j.10958312.2001.tb01355.x

Smith, K. (2003). Time's arrow: heterochrony and the evolution of development. Int. J. Dev. Biol. 47, 613-621.

Takhtajan, A. (1976). "Neoteny and the origin of flowering plants," in Origin and Early Evolution of Angiosperms, ed. C. B. Beck (New York: Columbia University Press), 207-218.

Todesco, M., Rubio-Somoza, I., Paz-Ares, J., and Weigel, D. (2010). A collection of target mimics for comprehensive analysis of microRNA function in Arabidopsis thaliana. PLoS Genet. 6:e1001031. doi: 10.1371/journal.pgen.1001031

Vekemans, D., Viaene, T., Caris, P., and Geuten, K. (2012). Transference of function shapes organ identity in the dove tree inflorescence. New Phytol. 193, 216-228. doi: 10.1111/j.14698137.2011.03915.x

von Goethe, J. W. (1790). Versuch die Metamorphose der Pflanzen. Gotha Bergmany: C. W. Ettinger.

Wang, J. W., Czech, B., and Weigel, D. (2009). miR156-regulated SPL transcription factors define an endogenous flowering pathway in Arabidopsis thaliana. Cell 138, 738-749. doi: 10.1016/j.cell.2009. 06.014

Wang, J. W., Park, M. Y., Wang, L. J., Koo, Y., Chen, X. Y., Weigel, D., et al. (2011). miRNA control of vegetative phase change in trees. PLoS Genet. 7:e1002012. doi: 10.1371/ journal.pgen.1002012

Webster, M., and Zelditch, M. L. (2005). Evolutionary modifications of ontogeny: heterochrony and beyond. Paleobiology 31, 354-372. doi: 10.1666/0094-8373(2005)031[0354: EMOOHA]2.0.CO;2

Wilkinson, M., de Andrade Silva, E., Zachgo, S., Saedler, H., and SchwarzSommer, Z. (2000). CHORIPETALA and DESPENTEADO: general regulators during plant development and potential floral targets of FIMBRIATA-mediated degradation. Development 127, 37253734.

Wingen, L. U., Münster, T., Faigl, W., Deleu, W., Sommer, H., Saedler, H., et al. (2012). Molecular genetic basis of pod corn (Tunicate maize). Proc. Natl. Acad. Sci. U.S.A 109, 7115-7120. doi: 10.1073/pnas. 1111670109

Wollmann, H., Mica, E., Todesco, M., Long, J. A., and Weigel, D. (2010). On reconciling the interactions between APETALA2, miR172 and AGAMOUS with the ABC model of flower development. Development 137, 3633-3642. doi: 10.1242/dev. 036673

Wu, G., Park, M. Y., Conway, S. R., Wang, J. W., Weigel, D., and Poethig, R. S. (2009). The sequential action of miR156 and miR172 regulates developmental timing in Arabidopsis. Cell 138, 750-759. doi: 10.1016/j.cell.2009. 06.031

Wu, G., and Poethig, R. S. (2006). Temporal regulation of shoot development in Arabidopsis thaliana by miR156 and its target SPL3. Development 133, 3539-3547. doi: 10.1242/ dev.02521

Yamaguchi, A., and Abe, M. (2012). Regulation of reproductive developmen by non-coding RNA in Arabidopsis: to flower or not to flower. J. Plant Res. 125, 693-704. doi: 10.1007/s10265012-0513-7

Yang, L., Xu, M., Koo, Y., He, J., and Poethig, R. S. (2013). Sugar promote vegetative phase change in Arabidopsis thaliana by repressing the expression of MIR156A and MIR156C. eLife, 2, e00260. doi: 10.7554/eLife. 00260

Yu, S., Cao, L., Zhou, C. M. Zhang, T. Q., Lian, H., Sun, Y., etal. (2013). Sugar is an endogenous cue for juvenile-toadult phase transition in plants eLife 2, e00269. doi: 10.7554/eLife. 00269

Yumul, R. E., Kim, Y. J., Liu, X., Wang, R., Ding, J., Xiao, L., et al. (2013). POWERDRESS and diversified expression of the MIR172 gene family bolster the floral stem cell network. PLoS Genet. 9:e1003218. doi: 10.1371/journal. pgen.1003218

Zhou, X., Wang, G., and Zhang, W. (2007). UV-B responsive microRNA genes in Arabidopsis thaliana. Mol. Syst. Biol. 3, 103. doi: 10.1038/ msb4100143

Zhu, Q. H., and Helliwell, C. A. (2011). Regulation of flowering time and floral patterning by miR172. J. Exp. Bot. 62, 487-495. doi: 10.1093/jxb/ erq295

Zotz, G., Wilhelm, K., and Becker, A. (2011). Heteroblasty - a review. Bot. Rev. 77, 109-151. doi: 10.1007/ s12229-010-9062-8

Conflict of Interest Statement: The authors declare that the research was conducted in the absence of any commercial or financial relationships that could be construed as a potential conflict of interest.

Received: 03 June 2013; accepted: 06 September 2013; published online: 25 September 2013

Citation: Geuten K and Coenen H (2013)

Heterochronic genes in plant evolution and development. Front. Plant Sci. 4:381. doi: 10.3389/fpls.2013.00381

This article was submitted to Plant Evolution and Development, a section of the journal Frontiers in Plant Science. Copyright (c) 2013 Geuten and Coenen. This is an open-access article distributed under the terms of the Creative Commons Attribution License (CC BY). The use, distribution or reproduction in other forums is permitted, provided the original author(s) or licensor are credited and that the original publication in this journal is cited, in accordance with accepted academic practice. No use, distribution or reproduction is permitted which does not comply with these terms. 